\title{
VARIABILIDADE ESPACIAL DA PRODUTIVIDADE DE SORGO E DE ATRIBUTOS DO SOLO NA REGIÃO DO ECÓTONO CERRADO-PANTANAL, MS
}

\author{
Rafael Montanari ${ }^{(1) *}$, Elói Panachuki ${ }^{(2)}$, Lenon Henrique Lovera ${ }^{(3)}$, Adriany Rodrigues \\ Correa $^{(3)}$, Israel Souza Oliveira ${ }^{(2)}$, Hernandes Andrade Queiroz ${ }^{(3)}$ e Pamela Kerlyane Tomaz $^{(1)}$
}

(1) Universidade Estadual Paulista, Faculdade de Engenharia, Campus de Ilha Solteira, Ilha Solteira, São Paulo, Brasil.

(2) Universidade Estadual de Mato Grosso do Sul, Departamento de Agronomia, Unidade de Aquidauana, Aquidauana, Mato Grosso do Sul, Brasil.

(3) Universidade Estadual Paulista, Faculdade de Engenharia, Programa de Pós-Graduação em Sistemas de Produção, Campus de Ilha Solteira, Ilha Solteira, São Paulo, Brasil.

* Autor correspondente.

E-mail: montanari@agr.feis.unesp.br

\section{RESUMO}

O Sorghum bicolor (L.) Moech é uma importante forrageira de alta produção, que cresce no cenário brasileiro ainda de forma lenta em substituição ao cultivo de milho safrinha. A cultura do sorgo seria alternativa no período da seca na produção de silagem para o período das águas; contudo, o crescimento e desenvolvimento das plantas pode ser influenciado por alterações nos atributos do solo, como textura, porosidade e estrutura do solo. $O$ objetivo deste trabalho foi analisar e caracterizar a dependência e variabilidade espacial entre atributos do solo e a cultura do sorgo forrageiro, em um Planossolo Hidromórfico no ecótono Cerrado-Pantanal. Para tanto, estimaram-se a produtividade de matérias verde e seca de forragem (MVF e MSF) de sorgo forrageiro e os atributos do solo, como macroporosidade (Ma), microporosidade (Mi), porosidade total $(\mathrm{Pt})$, diâmetro médio geométrico, diâmetro médio ponderado, índice de estabilidade de agregados (IEA) e teor de carbono orgânico total do solo (COT), em duas profundidades: $1(0,00-0,10 \mathrm{~m})$ e $2(0,10-0,20 \mathrm{~m})$. Em relação à malha geoestatística, foram realizadas 50 coletas de atributos de planta e solo em $40 \mathrm{ha}$. Isso possibilitou detectar a elevada variabilidade espacial dos atributos de planta (MVF e MSF) e também os atributos do solo que mais variaram espacialmente. Com relação às variáveis que apresentaram dependência espacial, o coeficiente de determinação $\left(r^{2}\right)$ decresceu na seguinte ordem: IEA1, silte2, Ma1, Pt1, areia2, silte1, MSF, argila1, MVF e IEA2. Com isso, verificou-se que IEA1 apresentou o melhor ajuste semivariográfico $\left(r^{2}=0,926\right)$, com alcance de $677,0 \mathrm{~m}$, e o avaliador da dependência espacial 
(50,6 \%) moderado. O silte1, porém, evidenciou o menor alcance $(111,0 \mathrm{~m})$ e, assim, recomenda-se que em estudos posteriores o alcance mínimo a ser adotado, para esse tipo de avaliação, não deve ser inferior a esse valor em Planossolo Hidromórfico sob preparo convencional. A correlação linear foi significativa e elevada para MVF e MSF, ao passo que entre atributos de planta versus solo houve correlações positiva e negativa. No âmbito da cokrigagem, a argila1 foi o melhor indicador para estimar a variabilidade espacial da produtividade de massa seca de forragem de sorgo de correlação significativa e negativa $(r=-0,292 *)$.

Palavras-chave: Planossolo Hidromórfico, preparo convencional, Sorghum bicolor (L.) Moech.

\section{ABSTRACT: SPATIAL VARIABILITY OF SORGHUM YIELD AND SOIL PROPERTIES IN THE REGION OF THE SAVANNA-WETLAND ECOTONE IN MATO GROSSO DO SUL, BRAZIL}

Sorghum bicolor (L.) Moech is an important high production forage crop that is increasingly used in Brazil, though still slow in replacing growing of second crop maize. Growing sorghum during the dry season would be an alternative for silage production and its use in the rainy season. However, plant growth and development will be affected if alterations occur in the texture, porosity, and structure of the soil. The objective of this study was to analyze the spatial variability and linear correlation between forage sorghum yield and soil properties in the 2011/2012 crop year in an Albaqualf soil in the region of the savanna-wetland ecotone. Thus, we estimated the fresh matter yield and dry matter yield (FMY and DMY) of forage sorghum and soil properties such as macroporosity (Ma), microporosity (Mi), total porosity (Pt), geometric mean diameter, weighted mean diameter, aggregate stability index (ASI), and the total organic carbon (TOC) content at two depths: $1(0.00-0.10 \mathrm{~m})$ and $2(0.10-0.20 \mathrm{~m})$. Fifty collections of plant and soil properties were conducted in 40 ha to form a geostatistical grid. This made it possible to find high spatial variability of plant production (FMY and DMY) and also the observation of soil properties that are most varied spatially. Concerning the variables that showed spatial dependence, the coefficient of determination $\left(r^{2}\right)$ decreased in the following order: ASI1, silt2, Ma1, Pt1, sand2, silt1, DMY, clay1, FMY and ASI2. Thus, we found that ASI1 showed the best semivariogram fit $\left(r^{2}=0.926\right)$, with a range of $677.0 \mathrm{~m}$, and moderate evaluation of spatial dependence (50.6\%). Silt1, however, had the lowest range $(111.0 \mathrm{~m})$, and thus it is recommended that in future studies the minimum range to be adopted for this type of evaluation should not be less than this value in an Albaqualf under conventional tillage. Linear correlation was highly significant and high for FMY and DMY, whereas in the interaction plant production versus soil properties there were positive and negative correlations. Within cokriging, clay 1 was the best indicator for estimating the spatial variability of dry matter yield of sorghum forage with a significant and negative $\left(r=-0.292^{*}\right)$ correlation.

Keywords: Albaqualf, conventional tillage, Sorghum bicolor (L.) Moech.

\section{INTRODUÇÃO}

O Pantanal sul mato-grossense é uma planície inundável, principalmente entre o período de janeiro a junho. Essa inundação que ocorre nesse local, denominado de região de campos alagados, é resultante da precipitação pluvial na região do planalto da Bacia do Alto Paraguai. Aliado a isso, a economia regional, que tem a pecuária como uma das principais atividades de exploração, é muito influenciada em razão da redução da disponibilidade de forragem no campo para os animais, ficando condicionado ao produtor produzir a forragem na época de seca ou realizar a retirada dos animais da região (Montanari et al., 2013).

O Sorghum bicolor (L.) Moech é uma importante forrageira de alta produção, que cresce no cenário brasileiro ainda de forma lenta em substituição ao cultivo de milho safrinha. A cultura apresenta características nutricionais semelhantes às da do milho, custo de produção inferior e possibilidade do fornecimento de forragem in natura ou de silagem, com tolerância à seca, às elevadas temperaturas e condições de solo compactado (Basso et al., 2011; CONAB, 2012; Montanari et al., 2013). A cultura, portanto, seria uma alternativa no período da seca na produção de silagem para o período das águas.

No ano agrícola de 2011/2012, a produção nacional brasileira obtida foi de 2,0 milhões de toneladas de grãos de sorgo; $3,4 \%$ desse total corresponderam à produção do Estado de Mato Grosso do Sul (CONAB, 2012). Na safra 2012/2013, a produção nacional teve incremento de 2,1 milhões de toneladas (CONAB, 2013). 
O cultivo em preparo convencional em Planossolo foi observado por Lima et al. (2008) e Bamberg et al. (2009), os quais identificaram a redução da produtividade de espécies agrícolas, principalmente pela baixa drenagem desse solo, que é causada pelo efeito do adensamento que reduz, especialmente, a macroporosidade $\left(<0,10 \mathrm{~m}^{3} \mathrm{~m}^{-3}\right)$ e favorece a ocorrência do processo erosivo sempre que a intensidade de precipitação pluvial supera a capacidade de infiltração de água no horizonte B. Esses autores ainda comentaram que a eluviação de silte e argila do tipo 2:1 expansiva em presença de água e de microagregados é a principal causa da redução da macroporosidade do solo, bem como da condutividade hidráulica.

Diversos autores (Basso et al., 2011; Silva Neto et al., 2011a; Silva Neto et al., 2011b) procuraram esclarecer a relação existente entre atributos de planta e de solo por meio da geoestatística, que é uma ferramenta que vem sendo muito utilizada nesses tipos de estudos, a fim de identificar as variáveis dependentes que apresentam variabilidade espacial e que influenciariam na tomada de decisão quanto às práticas de manejo do solo e da cultura, evidenciando melhores resultados no incremento de produtividade e mantendo ou melhorando a qualidade do solo.

Para Pedrotti e Mello Júnior (2009), a água, o oxigênio, a temperatura e a resistência mecânica à penetração de raízes são fatores que estão associados à emergência de plantas e ao crescimento radicular, atuando diretamente no desenvolvimento aéreo. Assim, havendo alteração na textura, porosidade e estrutura do solo, por sua vez, há interferência diretamente nos fatores citados anteriormente e indiretamente no crescimento de plantas.

No âmbito da geoestatística, o estudo da técnica auxilia os programas computacionais empregados na agricultura de precisão; ou seja, os dados gerados e ajustados da interpolação simples de dados (krigagem) e da interpolação cruzada (cokrigagem) entre atributos de planta versus solo servem como base para estimar a variabilidade espacial de determinada variável por meio de outra com facilidade de determinação.

O solo é um sistema heterogêneo e isso reflete diretamente na produtividade agrícola (Basso et al., 2011; Dalchiavon et al., 2011). Entretanto, essa variabilidade espacial pode ser reduzida com o emprego de práticas de manejo do solo de acordo com a necessidade de cada região amostrada. A aplicação em taxas variáveis de correção do solo, fertilizantes, semeadura, tratamento químico, entre outras, reduz o custo que seria gerado nas regiões onde não haveria necessidade de realização das práticas na mesma proporção.

Diante do exposto, este trabalho teve como objetivos analisar e caracterizar a dependência e variabilidade espacial entre atributos do solo e a cultura do sorgo forrageiro, em um Planossolo Hidromórfico no ecótono Cerrado-Pantanal.

\section{MATERIAL E MÉTODOS}

O estudo foi conduzido no ano agrícola 2011/2012 em área de produção da fazenda Bodoquena, pertencente ao Grupo Votorantim, localizada no município de Miranda, MS, Brasil, situada nas coordenadas geográficas (UTM) $520.070 \mathrm{~N}$ e 7.795.19 3E, altitude média de $111,0 \mathrm{~m}$. O clima da região, segundo Köppen (1931), é tropical subúmido do tipo Aw, com estações bem-definidas, sendo chuvosa no verão e seca no inverno, e precipitação pluvial anual variando entre 800 e $1.200 \mathrm{~mm}$ (Embrapa, 2002).

Para a caracterização química e granulométrica inicial (Quadro 1) da área amostrada, coletaram-se 25 amostras simples para obter três amostras compostas no talhão para a malha geoestatística na camada de 0,00-0,20 m. A caracterização química do solo (Quadro 1) foi realizada na Empresa Brasileira de Pesquisa Agropecuária (Embrapa-CPAO), localizada na cidade de Dourados, MS.

\section{Preparo da área}

A área experimental foi manejada em sistema de preparo convencional, com preparo do solo e semeadura no ano agrícola de 2011/2012, adotando o espaçamento de cultivo entrelinhas de $0,75 \mathrm{~m}$ e densidade de plantas de 14 plantas $\mathrm{m}^{-1}$. No momento da semeadura do híbrido Volumax, semiprecoce, foram aplicados $230 \mathrm{~kg} \mathrm{ha}^{-1}$ de NPK + Zn na formulação 08-20-20 + 0,5\%.

A locação dos pontos amostrais para a coleta de dados foi realizada 130 dias após a emergência (DAE) das plântulas em uma área de 40 ha, sendo os pontos distribuídos aleatoriamente e georreferenciados por meio de um receptor GPS, com precisão de 1,0 a 3,0 m.

\section{Atributos de planta}

Em cada ponto amostral, entre os dias 18 e 20/04/2011, foram coletadas amostras de plantas numa área correspondente a $0,64 \mathrm{~m}^{2}$ $(0,80 \times 0,80 \mathrm{~m})$, de forma que cada ponto ficasse no meio das entrelinhas $(0,72 \mathrm{~m})$ para determinar a produtividade de matéria verde (MVF) e seca de forragem (MSF). O corte da forrageira foi feito na altura de $0,30 \mathrm{~m}$ e picagem em colhedora de forragem modelo JF Double Z20 em diâmetros, variando de 10 a $15 \mathrm{~mm}$, utilizado para produção de silagem de sorgo forrageiro. A partir desse material picado e homogeneizado, retirou-se $1 \mathrm{~kg}$ para quantificação da MVF e MSF $\left(\mathrm{kg} \mathrm{ha}^{-1}\right)$, essa obtida após secagem em estufa a $60^{\circ} \mathrm{C}$ por um período de $72 \mathrm{~h}$. 
Quadro 1. Caracterização química e granulométrica do Planossolo Hidromórfico na camada de 0,00-0,20 cm

\begin{tabular}{|c|c|c|c|c|c|c|c|c|c|c|c|}
\hline \multirow[t]{2}{*}{ Prof. } & \multirow[t]{2}{*}{ Areia } & \multirow[t]{2}{*}{ Silte } & \multirow[t]{2}{*}{ Argila } & \multicolumn{2}{|c|}{ pH } & \multirow[t]{2}{*}{$\mathbf{P}$} & \multirow[t]{2}{*}{$\mathbf{K}^{+}$} & \multirow[t]{2}{*}{$\mathrm{Ca}^{2+}$} & \multirow[t]{2}{*}{$\mathrm{Mg}^{2+}$} & \multirow[t]{2}{*}{$\mathrm{Al}^{3+}$} & \multirow[t]{2}{*}{$\mathrm{H}+\mathrm{Al}$} \\
\hline & & & & $\mathrm{H}_{2} \mathrm{O}$ & $\mathrm{CaCl}_{2}$ & & & & & & \\
\hline \multirow[b]{2}{*}{1} & & $\mathrm{~g} \mathrm{~kg}^{-1}$ & & & $1: 2,5$ & $\mathrm{mg} \mathrm{dm} \mathrm{m}^{-3}$ & \multicolumn{5}{|c|}{$\mathrm{cmol}_{\mathrm{c}} \mathrm{dm}^{-3}$} \\
\hline & 367 & 293 & 340 & 6,6 & 6,0 & 31,7 & 0,32 & 16,2 & 2,8 & 0,0 & 2,4 \\
\hline 2 & 400 & 294 & 306 & 6,8 & 6,2 & 32,2 & 0,26 & 15,9 & 2,3 & 0,0 & 2,4 \\
\hline \multirow[t]{3}{*}{3} & 384 & 310 & 306 & 6,6 & 6,0 & 20,7 & 0,29 & 13,0 & 2,3 & 0,0 & 2,5 \\
\hline & MO & SB & CTC & CTCef & $\mathrm{m}$ & $\mathrm{V}$ & $\mathrm{Cu}$ & $\mathrm{Fe}$ & $\mathrm{Mn}$ & $\mathrm{Zn}$ & \\
\hline & $\mathrm{g} \mathrm{kg}^{-1}$ & \multicolumn{3}{|c|}{$\mathrm{cmol}_{\mathrm{c}} \mathrm{dm}^{-3}$} & \multicolumn{2}{|c|}{$\%$} & \multicolumn{4}{|c|}{$\mathrm{mg} \mathrm{dm}^{-3}$} & \\
\hline 1 & 30,41 & 19,32 & 21,7 & 19,3 & 0 & 89 & 1,2 & 32,1 & 65,5 & 1,7 & \\
\hline 2 & 26,88 & 18,46 & 20,8 & 18,5 & 0 & 89 & 1,1 & 33,6 & 80,8 & 1,7 & \\
\hline 3 & 21,64 & 15,59 & 18,1 & 15,6 & 0 & 86 & 1,2 & 50,5 & 76,7 & 1,3 & \\
\hline
\end{tabular}

P, K, Cu, Fe, Mn e Zn: extrator Mehlich-1; Ca, Mg e Al: extrator KCl 1 mol L-1 ; H+Al: acetato de cálcio pH 7; MO: matéria orgânica, Método Dumas em analisador elementar; CTCef: capacidade de troca de cátions efetiva.

\section{Atributos do solo}

O solo onde a malha geoestatística foi instalada é um Planossolo Hidromórfico, de textura média e relevo levemente ondulado (Embrapa, 2013). As amostragens dos atributos da cultura do sorgo e do solo foram realizadas de maneira aleatória, contendo 51 pontos amostrais com espaçamento irregular, numa área de $610.000 \mathrm{~m}^{2}$. As coordenadas em UTM foram obtidas por meio do uso de um receptor GPS etrex.

As coletas de solo foram realizadas nas entrelinhas de cultivo para as camadas 1 $(0,00-0,10 \mathrm{~m})$ e $2(0,10-0,20 \mathrm{~m})$, determinando-se densidade da partícula (Dp), macroporosidade (Ma), microporosidade (Mi), porosidade total (Pt), granulometria do solo (areia, silte e argila) e carbono orgânico total do solo (COT) para cada ponto amostral, aplicando os métodos de coleta e práticas laboratoriais de acordo com Embrapa (1997). Em anéis de Kopecky de raio $=2,52 \mathrm{~cm}$ e altura $=5 \mathrm{~cm}$, foram coletadas as amostras de solo indeformadas para definir a Ma, Mi e Pt, submetendo a mesa de tensão, por $24 \mathrm{~h}$, à tensão de $6 \mathrm{kPa}$; essas foram secas em estufa à temperatura de $105^{\circ} \mathrm{C}$ por $36 \mathrm{~h}$, utilizando as expressões a seguir para cálculo:

$$
\begin{aligned}
& M a\left(m^{3} m^{-3}\right)=\frac{S s t-S u}{V t} \\
& M i\left(m^{3} m^{-3}\right)=\frac{S u-S S}{V t} \\
& \operatorname{Pt}\left(m^{3} m^{-3}\right)=\frac{S s t-S u}{V t}
\end{aligned}
$$

em que Sst corresponde à condição de solo saturado; $\mathrm{Su}$, ao solo úmido com teor de água correspondente à tensão de $6 \mathrm{kPa}$ na mesa de tensão; Ss, ao solo seco em estufa; e Vt, ao volume do anel.

A densidade da partícula (Dp) foi determinada a partir de $20 \mathrm{~g}$ de solo seco em estufa, pelo período de $12 \mathrm{~h}$, a $105^{\circ} \mathrm{C}$, depositado em balão volumétrico
(50 mL), adicionando-se álcool etílico aos $20 \mathrm{~g}$ de solo até completar o volume do balão, utilizando-se a expressão a seguir, em que Va é o volume da amostra.

$$
D p\left(k g d m^{-3}\right)=\frac{S s}{(50-V a)} \quad \text { Eq. } 4
$$

A avaliação da estabilidade de agregados também foi realizada para as profundidades citadas, com as coletas entre as linhas de cultivo, determinando-se o diâmetro médio geométrico (DMG), diâmetro médio ponderado (DMP) e índice de estabilidade de agregados (IEA). Os monólitos foram coletados nas dimensões aproximadas de 0,10 × 0,15 × 0,05 m, correspondentes respectivamente à profundidade, ao comprimento e à largura nas camadas de 0,00-0,10 e 0,10-0,20 m e deixando-se secar ao ar.

As amostras foram preparadas por meio da ruptura manual dos torrões, aplicando força no sentido de tração e nunca de compressão, de forma a identificar os pontos de cisalhamento dos agregados. As amostras foram passadas em peneira de $8 \mathrm{~mm}$, e o material retido na peneira de $4 \mathrm{~mm}$ foi utilizado nas análises, sendo separadas em duplicata as quantidades de $50 \mathrm{~g}$ de solo para determinar a umidade do solo e para as posteriores agitações via seca $(\mathrm{Vs})$ e via úmida $(\mathrm{Vu})$. Com isso, procederam-se as agitações via seca em agitador mecânico vibratório Solotest ${ }^{\circledR}$, na frequência de 10 oscilações $\mathrm{min}^{-1}$, ficando retido os agregados em peneiras de diâmetros de $2 ; 1 ; 0,5 ; 0,25 ;$ e $0,126 \mathrm{~mm}$.

$\mathrm{Na}$ agitação via úmida, as amostras foram umedecidas em papel-filtro por período de 5 min para que ocorresse a saturação por capilaridade, visando, com isso, a lenta expulsão do ar contido nos poros dos agregados, evitando-se, assim, o rompimento dos agregados pela expulsão do ar (explosão).

No agitador mecânico vertical tipo Yodder Solotest ${ }^{\mathbb{R}}$, as amostras foram submetidas à oscilação vertical de 0,04 m (altura) e à frequência de 
32 oscilações $\min ^{-1}$ por 15 min. Para as análises, foi utilizado o material retido nas peneiras de $2 ; 1$; 0,$5 ; 0,25$; e $0,126 \mathrm{~mm}$, que foram levados à estufa $\mathrm{e}$ submetidos à temperatura de $105^{\circ} \mathrm{C}$ por $24 \mathrm{~h}$. Após esse período, o material foi pesado e, na sequência, aplicadas as equações 5 e 6 (Kemper e Rosenau, 1986).

$$
\begin{array}{ll}
D M G=10^{x}, \text { sendo } x=\frac{\sum(n \log d)}{\sum n} & \text { Eq. } 5 \\
D M P=\sum_{i=}^{n}(\text { cp. } p) & \text { Eq. } 6
\end{array}
$$

em que $\mathrm{n}$ expressa a massa dos agregados retidos na peneira (g); d, o diâmetro médio de determinada classe de tamanho do agregado $(\mathrm{mm}) ; \mathrm{cp}$, o centro de cada classe de peneira $(\mathrm{mm})$; e p, a massa da amostra seca (g).

Assim, partindo do pressuposto que exista uma relação entre o diâmetro médio ponderado úmido (DMPu) e o diâmetro médio ponderado seco (DMPs) e que quanto mais próximo da unidade maior a resistência do agregado em resistir a energia de desagregação, pode-se pela expressão 7 determinar o índice de estabilidade de agregados (IEA) (Salton, 2005).

$$
I E A=\frac{D M P u}{D M P S}
$$

Para definir a granulométrica do solo, foi utilizado o método da pipeta, encontrando a fração correspondente de areia, silte e argila. Assim, a partir das $20 \mathrm{~g}$ de terra fina seca ao ar (TFSA) de cada amostra, realizaram-se as análises granulométricas em que foram adicionados $20 \mathrm{~mL}$ de hidróxido de sódio na concentração de $1 \mathrm{~mol} \mathrm{~L}^{-1}$ e $50 \mathrm{~mL}$ de água destilada, agitando pelo período de $16 \mathrm{~h}$ em Mesa Agitadora Orbital SOLAB, na frequência de $200 \mathrm{rpm}$.

No final do processo, foram lavadas em peneiras $(\varnothing=0,053 \mathrm{~mm})$ com água destilada, retendo a areia total (2,00-0,05 mm), e secas em estufa à temperatura de $105^{\circ} \mathrm{C}$ por $36 \mathrm{~h}$. A solução proveniente da lavagem da amostra foi colocada em proveta volumétrica e completado o volume com água destilada, até obter $1.000 \mathrm{~mL}$, agitando, manualmente, 40 vezes com o auxílio do anel perfurado, e deixando em repouso por 3 h30.

No fim do período, coletaram-se $10 \mathrm{~mL}$ da solução, numa profundidade máxima de $0,05 \mathrm{~m}$ para a argila, depositando em béquer; posteriormente, encaminharam-se para a secagem em estufa $\left(105^{\circ} \mathrm{C}\right)$ por $24 \mathrm{~h}$. Pesaram-se as amostras de areia, em balança semianalítica, e as de argila, em balança analítica, aplicando os cálculos 8,9 e 10 para determinar o teor de cada atributo, sendo a areia total (AG), o solo seco (Ss) e a argila (Ar), segundo análise descrita por Embrapa (1997).

O teor de carbono orgânico total (COT) foi quantificado segundo preceitos de Yeomans e Bremner (1988), com pesagem de $2 \mathrm{~g}$ das amostras de TFSA, moídas, peneiradas $(\varnothing=0,2 \mathrm{~mm})$ e pesadas em balança analítica. Nas amostras, foram adicionados $5 \mathrm{~mL}$ de solução de dicromato de potássio na concentração de $0,167 \mathrm{~mol} \mathrm{~L}^{-1}$ e de 7,5 mL de ácido sulfúrico, aquecendo as amostras à temperatura de $170{ }^{\circ} \mathrm{C}$ por $30 \mathrm{~min}$. Após o período, foram adicionados $80 \mathrm{~mL}$ de água destilada e mais cinco gotas de solução de Ferroin, titulando o volume até o ponto de viragem, com a solução de sulfato ferroso amoniacal na concentração de $0,2 \mathrm{~mol} \mathrm{~L}^{-1}$, adotando-se, portanto, as equações 12 e 13 para o cálculo do carbono orgânico total (COT).

$$
\begin{array}{ll}
A=\left[\frac{(\mathrm{Vba}-\mathrm{Vam}) \cdot(\mathrm{Vbn}-\mathrm{Vba})}{V b n}\right]+(\mathrm{Vba}-\mathrm{Vam}) & \text { Eq. } 8 \\
\operatorname{COT}\left(\mathrm{g} \mathrm{kg}^{-1}\right)=\frac{[(\mathrm{A}) \cdot 0,2.3 \cdot 1000]}{\text { massa da amostra }(\mathrm{mg})} & \text { Eq. } 9
\end{array}
$$

em que Vba é o volume gasto na titulação do branco (aquecido); Vbn, o volume gasto na titulação do branco-controle (sem aquecimento); e Vam, o volume gasto na titulação da amostra. $\mathrm{O}$ número 3 é o resultado da relação entre o número de mol de $\mathrm{Cr}_{2} \mathrm{O}_{7}^{-}$, que reage com $\mathrm{Fe}^{2+}(1 / 6)$, multiplicado pelo número de mol de $\mathrm{Cr}_{2} \mathrm{O}_{7}^{-}$, que reage com o $\mathrm{C}$ (3/2), multiplicado pela massa atômica do C (12); e o 1.000, o fator de conversão de unidade $\left(\mathrm{mg} \mathrm{mg}^{-1}\right.$ para $\left.\mathrm{g} \mathrm{k}^{-1}\right)$.

\section{Análise estatística e geoestatística}

A análise estatística inicial foi realizada pelo programa computacional SAS (Schlotzhaver e Littell, 1997). Assim, foram realizados os cálculos de média, moda, mediana, máximo, mínimo, desvio-padrão, coeficiente de variação, curtose e de assimetria. Além disso, foi realizado o teste Shapiro e Wilk (1965), significativos a 1 e $5 \%$, com a observação dos tipos de distribuição de frequência (normalidade - NO; tendendo à normalidade - TN; e indeterminados - IN).

Também foi montada a matriz de correlação, objetivando efetuar as correlações lineares simples para as combinações, duas a duas, entre todos os atributos estudados.

Os métodos clássicos de análise estatística de dados geralmente supõem que as realizações das variáveis aleatórias são independentes entre si, ou seja, que as observações vizinhas não exercem influência umas sobre as outras. Contudo, por meio do software $\mathrm{GS}^{+}$(2004), foi possível empregar a análise geoestatística, verificando as variações que ocorrem espacialmente entre os atributos de planta e do solo, que apresentam dependência espacial. De modo que, por meio da interpolação de dados simples, denominado de krigagem, e havendo correlação entre atributos de planta versus solo, a realização da cokrigagem entre os atributos secundários (qualitativos) apresentaram efeito sobre uma variável primária (quantitativo). 


\section{RESULTADOS E DISCUSSÃO}

$\mathrm{Na}$ análise descritiva dos atributos do solo para as camadas $1(0,00-0,10 \mathrm{~m})$ e $2(0,10-0,20 \mathrm{~m})$, foram considerados os preceitos de Pimentel-Gomes e Garcia (2002), utilizando o coeficiente de variação (CV) como resposta da variação do atributo em relação à média, sendo tanto maior seu valor quanto maior a variação entre eles. Assim, a precisão de uma avaliação pode ser medida pelo CV e quanto menor, maior a precisão.

De acordo com Pimentel-Gomes e Garcia (2002), pode-se classificar o $\mathrm{CV}$ em baixo ( $\mathrm{CV} \leq 10 \%$ ), médio $(10 \%<\mathrm{CV} \leq 20 \%)$, alto $(20 \%<\mathrm{CV} \leq 30 \%) \mathrm{e}$ muito alto $(\mathrm{CV}>30 \%)$ para os atributos analisados. Nesse sentido, a produtividade da cultura obteve uma variação alta (CV > $20 \%$ ) para as matérias verde (MVF) e seca da forragem (MSF) (Quadro 2); e, da mesma forma, para os atributos do solo como macroporosidade (Ma1 e Ma2), diâmetro médio geométrico (DMG1 e DMG2), diâmetro médio ponderado (DMP1), índice de estabilidade de agregados (IEA1 e IEA2) e carbono orgânico total do solo (COT1 e COT2) (Quadro 2). Esses atributos apresentaram alto grau de heterogeneidade, ou seja, variando entre um CV alto a muito alto (Cambardella et al., 1994; Polo e Garcia, 2010; Basso et al., 2011; Campos et al., 2013), enquanto as variáveis areia1, areia2, silte1, silte2, argila1, argila2, microporosidade (Mi1 e Mi2) e porosidade total do solo (Pt1 e Pt2) com intervalos baixos a médios, como encontrado por outros autores (Basso et al., 2011; Silva Neto et al., 2011a; Silva Neto et al., 2011b; Campos et al., 2013) em outras classes de solo, demonstrando que essas variáveis variam pouco espacialmente.

Por meio da distribuição de frequência, pôde-se visualizar o comportamento das variáveis em estudo, utilizando a média como a medida mais adequada para explicar a normalidade. Neste estudo, foram obtidas distribuições do tipo normal (NO) (MVF, MSF, areia1, areia2, silte1, silte2, argila1, argila2, Ma1, Mi2, Pt1, Pt2, Dp1, Dp2, DMP2, IEA1, IEA2 e COT1), tendendo à normalidade (TN) (Ma2, Mi1 e DMP1) e indeterminado (IN) (DMG1, DMG2 e COT2) (Quadro 2). Assim, as assimetrias dos atributos NO, quando positivas, ficaram estabelecidas de 0,023 a 0,646 e a curtose de 0,074 a 1,643 ; quando negativas de -0,036 a -0,412 e -0,058 a -0,538 (Quadro 2). Assim, pode-se considerar que os valores observados para essas variáveis foram semelhantes ao observado por Basso et al. (2011), os quais encontraram lognormalidade para a Ma2 e Mi1 e normalidade para as variáveis Pt1 e Pt2.

Os valores médios da produtividade de sorgo forrageiro foram de $106.832,0 \mathrm{~kg} \mathrm{ha}^{-1}$ (MVF) e $34.521,0 \mathrm{~kg} \mathrm{ha}^{-1}$ (MSF), sendo o valor da produtividade de matéria seca superior aos estudos realizados por Avelino (2009) e Basso et al. (2011).
Para Shatar e McBratney (1999), uma das principais causas da variação na produtividade de sorgo é a umidade do solo, influenciada pelo teor de argila e matéria orgânica do solo. Nos solos mais argilosos, há tendência de ocorrer maior $\mathrm{Mi}$, que favorece a maior retenção de água no solo e, assim, maior disponibilidade de água para as plantas. Além disso, as condições edafoclimáticas, época de plantio, espaçamento, altura de planta, colheita e uso (forragem, silagem ou grãos) são fatores que permitem encontrar valores de produtividade de MSF variando entre 27 e $45 \%$ da biomassa total do sorgo forrageiro (Avelino, 2009; Guareschi et al., 2010; Basso et al., 2011).

Em estudos realizados em áreas de cultivo em classe de Planossolo Háplico em sistema de preparo do solo convencional, tem-se observado a redução da Ma do solo em virtude da eluviação de argila e silte e de microagregados do solo (Lima et al., 2008; Bamberg et al., 2009). Segundo os autores, o revolvimento da camada arável $(0,00-0,20 \mathrm{~m})$ expõe os materiais cimentantes, acelerando a degradação, principalmente da matéria orgânica; por sua vez, reduzindo a estabilidade de agregados e aumentando a densidade do solo e a resistência mecânica à penetração de raízes no solo.

Nas camadas avaliadas de 0,00-0,10 e 0,10-0,20 m (Quadro 2) para areia, silte e argila, observou-se baixa diferença entre as duas faixas amostradas. Assim, as condições granulométricas encontradas foram as seguintes: argila $245>240 \mathrm{~g} \mathrm{~kg}^{-1}$, areia $361>359 \mathrm{~g} \mathrm{~kg}^{-1}$ e silte $395<400 \mathrm{~g} \mathrm{~kg}^{-1}$ (Quadro 2).

$\mathrm{O}$ valor médio da Ma do solo na tensão de $6 \mathrm{kPa}$ nas duas profundidades foi de $0,11 \mathrm{~m}^{3} \mathrm{~m}^{-3}$. Esse valor foi superior ao observado por Lima et al. (2008) em cultivo convencional em Planossolo Háplico e ficou próximo ao $0,10 \mathrm{~m}^{3} \mathrm{~m}^{-3}$ sugerido por Grable e Siemer (1968) como crítico ao desenvolvimento radicular, em razão da limitada difusão de oxigênio no solo para as plantas. Com relação à Mi e Pt do solo nas duas profundidades, os valores médios apresentaram leve redução em profundidade $\left(0,35>0,33 \mathrm{~m}^{3} \mathrm{~m}^{-3} \mathrm{Mi}\right.$; $0,46>0,45 \mathrm{~m}^{3} \mathrm{~m}^{-3} \mathrm{Pt}$ ).

Nesse sentido, Lier (2010) considerou que a porosidade de aeração pode variar entre 0,05 e $0,20 \mathrm{~m}^{3} \mathrm{~m}^{-3}$, sendo a energia demandada pela planta para produção de biomassa vegetal maior em virtude do aumento da temperatura, necessitando de maior fluxo de oxigênio para realização da respiração e de processos metabólicos que em condições de baixa porosidade torna-se limitante.

A área experimental apresentou elevada estabilidade de agregados pelo IEA superior a 70 (Quadro 2) nas duas profundidades. Assim, também foi observado para o diâmetro médio ponderado (DMP $>3,11 \mathrm{~mm}$ ) e o geométrico (DMG $>2,08 \mathrm{~mm}$ ) (Quadro 2) o aumento em profundidade. O DMP foi superior ao considerado crítico (DMP $<2,49 \mathrm{~mm}$ ) ao cultivo agrícola em Planossolo Háplico, conforme proposto por Lima et al. (2008). 
Quadro 2. Estatística descritiva inicial da produtividade de forragem de Sorghum bicolor, de atributos físicos e de carbono orgânico total (COT) de um Planossolo Hidromórfico

\begin{tabular}{|c|c|c|c|c|c|c|c|c|c|c|}
\hline \multirow[t]{2}{*}{ Atributo $^{(1)}$} & \multirow[t]{2}{*}{ Média } & \multirow[t]{2}{*}{ Mediana } & \multicolumn{2}{|c|}{ Valor } & \multirow{2}{*}{$\begin{array}{l}\text { Desvio } \\
\text { padrão }\end{array}$} & \multicolumn{3}{|c|}{ Coeficiente } & \multicolumn{2}{|c|}{ Probabilidade do teste $^{(2)}$} \\
\hline & & & Máximo & Mínimo & & Variação & Curtose & Assimetria & $\operatorname{Pr}<\mathbf{w}$ & DF \\
\hline & \multicolumn{10}{|c|}{$\%$} \\
\hline & \multicolumn{10}{|c|}{ Atributo de planta } \\
\hline MVF (kg ha $\left.{ }^{-1}\right)$ & $106.832,0$ & $109.375,0$ & $148.438,0$ & $54.688,0$ & $21.890,0$ & 20,5 & $-0,538$ & $-0,189$ & 0,394 & NO \\
\hline \multirow[t]{2}{*}{$\operatorname{MSF}\left(\mathrm{kg} \mathrm{ha}^{-1}\right)$} & $34.521,0$ & $34.369,0$ & $46.811,0$ & $17.762,0$ & $6.994,0$ & 20,2 & $-0,432$ & $-0,234$ & 0,620 & NO \\
\hline & \multicolumn{10}{|c|}{ Textura } \\
\hline Areia1 $\left(\mathrm{g} \mathrm{kg}^{-1}\right)$ & 361 & 367 & 455 & 250 & 45,0 & 12,4 & $-0,374$ & $-0,198$ & 0,926 & NO \\
\hline Areia2 $\left(\mathrm{g} \mathrm{kg}^{-1}\right)$ & 359 & 362 & 441 & 246 & 41,5 & 11,7 & 0,074 & $-0,336$ & 0,564 & NO \\
\hline Silte1 $\left(\mathrm{g} \mathrm{kg}^{-1}\right)$ & 395 & 388 & 525 & 284 & 47 & 12,0 & 0,847 & 0,646 & 0,084 & NO \\
\hline Silte2 $\left(\mathrm{g} \mathrm{kg}^{-1}\right)$ & 400 & 394 & 499 & 268 & 46,7 & 11,6 & 0,336 & $-0,036$ & 0,230 & NO \\
\hline Argila $1\left(\mathrm{~g} \mathrm{~kg}^{-1}\right)$ & 245 & 246 & 400 & 151 & 46,8 & 19,0 & 1,615 & 0,518 & 0,105 & NO \\
\hline \multirow[t]{2}{*}{ Argila $2\left(\mathrm{~g} \mathrm{~kg}^{-1}\right)$} & 240 & 239 & 400 & 144 & 48,2 & 20,0 & 1,643 & 0,632 & 0,115 & NO \\
\hline & \multicolumn{10}{|c|}{ Porosidade do solo } \\
\hline $\operatorname{Ma} 1\left(\mathrm{~m}^{3} \mathrm{~m}^{-3}\right)$ & 0,108 & 0,112 & 0,180 & 0,021 & 0,03 & 34,0 & $-0,091$ & $-0,412$ & 0,170 & NO \\
\hline $\operatorname{Ma} 2\left(\mathrm{~m}^{3} \mathrm{~m}^{-3}\right)$ & 0,110 & 0,119 & 0,190 & 0,029 & 0,040 & 36,0 & $-0,471$ & $-0,456$ & 0,033 & $\mathrm{TN}$ \\
\hline $\operatorname{Mi} 1\left(\mathrm{~m}^{3} \mathrm{~m}^{-3}\right)$ & 0,350 & 0,345 & 0,496 & 0,272 & 0,041 & 11,9 & 2,612 & 1,245 & 0,029 & $\mathrm{TN}$ \\
\hline $\operatorname{Mi} 2\left(\mathrm{~m}^{3} \mathrm{~m}^{-3}\right)$ & 0,338 & 0,334 & 0,416 & 0,239 & 0,036 & 11,0 & $-0,058$ & 0,091 & 0,315 & NO \\
\hline $\operatorname{Pt} 1\left(\mathrm{~m}^{3} \mathrm{~m}^{-3}\right)$ & 0,459 & 0,459 & 0,595 & 0,318 & 0,051 & 11,3 & 0,892 & 0,023 & 0,688 & NO \\
\hline \multirow[t]{2}{*}{$\operatorname{Pt} 2\left(\mathrm{~m}^{3} \mathrm{~m}^{-3}\right)$} & 0,448 & 0,453 & 0,525 & 0,360 & 0,037 & 8,0 & 0,217 & $-0,326$ & 0,426 & NO \\
\hline & \multicolumn{10}{|c|}{ Densidade da partícula } \\
\hline $\operatorname{Dp} 1\left(\mathrm{~kg} \mathrm{dm}^{-3}\right)$ & 2,656 & 2,667 & 2,857 & 2,469 & 0,092 & 3,5 & $-0,440$ & $-0,220$ & 0,274 & NO \\
\hline \multirow[t]{2}{*}{$\mathrm{Dp} 2\left(\mathrm{~kg} \mathrm{dm}^{-3}\right)$} & 2,656 & 2,667 & 2,900 & 2,400 & 0,102 & 3,8 & $-0,219$ & $-0,145$ & 0,145 & NO \\
\hline & \multicolumn{10}{|c|}{ Estabilidade de agregados } \\
\hline DMG $1(\mathrm{~mm})$ & 2,084 & 1,970 & 3,870 & 0,650 & 0,675 & 32,4 & 0,982 & 0,761 & 0,010 & IN \\
\hline DMG $2(\mathrm{~mm})$ & 2,108 & 2,000 & 3,950 & 1,110 & 0,629 & 29,8 & 0,563 & 0,906 & 0,011 & IN \\
\hline DMP $1(\mathrm{~mm})$ & 3,110 & 3,080 & 4,470 & 0,920 & 0,679 & 21,8 & 1,900 & $-0,553$ & 0,026 & $\mathrm{TN}$ \\
\hline DMP $2(\mathrm{~mm})$ & 3,133 & 3,050 & 4,500 & 1,900 & 0,577 & 18,4 & $-0,323$ & 0,346 & 0,058 & NO \\
\hline IEA 1 & 0,713 & 0,700 & 1,220 & 0,200 & 0,185 & 26,0 & 1,333 & 0,036 & 0,294 & NO \\
\hline \multirow[t]{2}{*}{ IEA 2} & 0,746 & 0,760 & 1,140 & 0,420 & 1,590 & 21,3 & $-0,170$ & 0,135 & 0,920 & NO \\
\hline & \multicolumn{10}{|c|}{ Carbono orgânico total } \\
\hline $\operatorname{COT} 1\left(\mathrm{~g} \mathrm{~kg}^{-1}\right)$ & 17,90 & 18,00 & 31,90 & 1,30 & 6,726 & 37,4 & $-0,153$ & $-0,374$ & 0,773 & NO \\
\hline $\operatorname{COT} 2\left(\mathrm{~g} \mathrm{~kg}^{-1}\right)$ & 21,40 & 21,40 & 51,50 & 7,17 & 7,671 & 35,8 & 3,522 & 1,085 & 0,090 & IN \\
\hline
\end{tabular}

(1) Atributos de planta (MVF: produtividade de matéria verde de forragem e MSF: produtividade de matéria seca de forragem) e atributos físicos e químico de solo (Ma: macroporosidade, Mi: microporosidade, Pt: porosidade total, Dp: densidade de partícula, DMG: diâmetro médio geométrico, DMP: diâmetro médio ponderado, IEA: índice de estabilidade de agregados e COT: carbono orgânico total) avaliados nas camadas $1(0,00-0,10 \mathrm{~m})$ e $2(0,10-0,20 \mathrm{~m})$; e ${ }^{(2)} \mathrm{DF}$ : distribuição de frequência, sendo NO, IN e TN, correspondentes à normalidade, indeterminado e tendendo à normalidade.

Segundo Castro Filho et al. (1998), o COT do solo apresenta relação direta com o DMP e DMG desse solo. Assim, havendo incremento de resíduos vegetais na superfície, há aumento do teor de C orgânico do solo, melhorando, sobretudo o estado de agregação do solo. Isso contrastou com o aumento em profundidade do COT (0,00-0,10 m - 17,90 $\mathrm{g} \mathrm{kg}^{-1}$; 0,10-0,20 m - 21,40 $\mathrm{g} \mathrm{kg}^{-1}$ ).

No quadro 3 , foi apresentada a matriz de correlação linear simples entre os atributos de sorgo e os do solo. Na análise do par MVF versus MSF, verificou-se correlação alta e positiva $(r=0,890 * *)$, concordando com Basso et al. (2011). Isso demonstrou que havendo o incremento de matéria verde da forragem ocorre o aumento da produtividade de matéria seca; portanto, nas condições desta pesquisa, pode-se estimar a produtividade de MSF por meio da MVF.

Os atributos do solo apresentaram correlações significativas positivas (MVF $\times$ areia $1, r=0,279^{*}$ e MSF $\times$ areia $1, r=0,375^{* *}$ ) e negativas $\left(\mathrm{MSF} \times\right.$ argila $1, \mathrm{r}=-0,292^{*}$ e MSF $\times$ MO1, 
$r=0,332 *$ com a produtividade do sorgo forrageiro. Diferente deste trabalho, Basso et al. (2011) verificaram correlações positivas entre os atributos de planta versus a porosidade do solo em Latossolo Vermelho distroférrico, em Dourados, MS. Entre os atributos do solo avaliados, o aumento da argila e do COT do solo proporcionou aumento da Mi do solo em virtude de sua capacidade em favorecer a agregação do solo (Quadro 3).

A autocorrelação possibilitou a estimativa da dependência espacial de amostras vizinhas, considerando-se, portanto, o quanto a presença de uma variável aleatória é capaz de influenciar seus vizinhos espacialmente. Por meio do semivariograma simples, foi possível expressar o comportamento da variável regionalizada ou de seus resíduos, demonstrando o tamanho da zona de influência em torno de uma amostra e a variação e a continuidade nas diferentes direções do espaço (Isaaks e Srivastava, 1989).
Analisando o quadro 4, foi possível observar as variáveis que apresentaram efeito pepita puro $\left(\mathrm{C}_{0}=\mathrm{C}+\mathrm{C}_{0}\right)$ (areia1, argila2, Ma2, Mi1, Mi2, Pt2, Dp1, Dp2, DMG1, DMG2, DMP1, DMP2, MO1 e MO2), ou seja, sem dependência espacial. Entretanto, com base na eficiência do coeficiente de determinação espacial $\left(\mathrm{r}^{2}\right)$, verificou-se nos semivariogramas simples que o $\mathrm{r}^{2}$ decresceu na seguinte ordem: IEA1 $(0,926)$, silte $2(0,921)$, Ma1 $(0,872)$, Pt1 $(0,857)$, areia2 $(0,788)$, silte1 $(0,718)$, MSF $(0,701)$, argila1 $(0,689), \operatorname{MVF}(0,589)$ e IEA2 $(0,444)$ (Figura 1, Quadro 4). Com relação aos atributos avaliados, observou-se que, para o IEA1, o $\mathrm{r}^{2}$ de 0,926 representou o melhor ajuste semivariográfico. O avaliador da dependência espacial (ADE) (Robertson, 1998) observado (50,6 \%) foi moderado, com alcance de $677,0 \mathrm{~m}$ e com ajuste gaussiano.

Com referência ao alcance, ficou estabelecido em ordem decrescente: IEA1 $(677,0 \mathrm{~m}), \mathrm{MSF}$ $(469,0 \mathrm{~m})$, argila1 $(389,0 \mathrm{~m})$, areia2 $(232,0 \mathrm{~m})$,

Quadro 3. Matriz de correlação linear simples entre a produtividade de forragem de sorgo e de atributos físicos e de carbono orgânico total de um Planossolo Hidromórfico

\begin{tabular}{|c|c|c|c|c|c|c|c|c|}
\hline Atributo $^{(1)}$ & MVF & MSF & Areia1 & Areia2 & Silte1 & Silte2 & Argila1 & Argila2 \\
\hline MSF & $0,890 * *$ & - & - & - & - & - & - & - \\
\hline Areia1 & $0,279^{*}$ & $0,375^{* *}$ & - & - & - & - & - & - \\
\hline Areia2 & 0,218 & 0,244 & $0,816^{* *}$ & - & - & - & - & - \\
\hline Silte1 & $-0,024$ & $-0,068$ & $-0,471^{* *}$ & $-0,286^{*}$ & - & - & - & - \\
\hline Silte2 & $-0,044$ & $-0,039$ & $-0,149$ & $-0,378^{* *}$ & $0,486^{* *}$ & - & - & - \\
\hline Argila1 & $-0,243$ & $-0,292^{*}$ & $-0,473^{* *}$ & $-0,485^{* *}$ & $-0,550 * *$ & $-0,333^{*}$ & - & - \\
\hline Argila2 & $-0,170$ & $-0,200$ & $-0,521^{* *}$ & $-0,456^{* *}$ & $-0,224$ & $-0,630^{* *}$ & $0,714^{* *}$ & - \\
\hline $\mathrm{Ma} 2$ & $-0,009$ & 0,014 & $0,281^{*}$ & $0,313^{*}$ & 0,195 & 0,118 & $-0,462^{* *}$ & $-0,363^{* *}$ \\
\hline Mi1 & $-0,074$ & $-0,065$ & $-0,441^{* *}$ & $-0,467 * *$ & 0,000 & 0,102 & $0,435^{* *}$ & $0,344^{*}$ \\
\hline Mi2 & $-0,056$ & $-0,086$ & $-0,342^{*}$ & $-0,512^{* *}$ & $-0,031$ & 0,121 & $0,350^{*}$ & $0,293^{*}$ \\
\hline PT1 & $-0,060$ & 0,001 & $-0,351^{*}$ & $-0,439 * *$ & 0,135 & 0,160 & 0,204 & 0,242 \\
\hline DMG1 & $-0,098$ & $-0,027$ & $-0,175$ & $-0,204$ & $-0,080$ & $-0,148$ & 0,246 & $0,312^{*}$ \\
\hline IEA1 & $-0,128$ & $-0,055$ & $-0,099$ & $-0,168$ & $-0,079$ & $-0,186$ & 0,171 & $0,313^{*}$ \\
\hline \multirow[t]{2}{*}{ COT1 } & $-0,267$ & $-0,332^{*}$ & $-0,297^{*}$ & $-0,264$ & 0,185 & 0,096 & 0,101 & 0,127 \\
\hline & Ma1 & $\mathrm{Ma} 2$ & Mi1 & Mi2 & DMG1 & DMG2 & DMP1 & DMP2 \\
\hline $\mathrm{Mi} 2$ & 0,008 & $-0,537^{* *}$ & $0,668^{* *}$ & - & - & - & - & - \\
\hline Pt1 & $0,575^{* *}$ & $-0,127$ & $0,720^{* *}$ & $0,527^{* *}$ & - & - & - & - \\
\hline Pt2 & $0,419^{* *}$ & $0,543^{* *}$ & 0,115 & $0,415^{* *}$ & - & - & - & - \\
\hline DMG1 & $-0,281^{*}$ & $-0,286^{*}$ & 0,250 & 0,120 & - & - & - & - \\
\hline COT1 & $-0,150$ & $-0,075$ & $0,290^{*}$ & 0,161 & - & - & - & - \\
\hline DMP1 & $-0,194$ & $-0,182$ & 0,188 & 0,054 & $0,362^{* *}$ & - & - & - \\
\hline DMP2 & $-0,125$ & $-0,026$ & 0,089 & $-0,164$ & $0,963^{* *}$ & $0,380^{* *}$ & - & - \\
\hline IEA1 & $-0,070$ & $-0,168$ & 0,144 & 0,119 & $0,357^{*}$ & $0,983^{* *}$ & $0,374^{* *}$ & - \\
\hline IEA2 & $-0,006$ & 0,046 & 0,017 & $-0,199$ & $0,744^{* *}$ & $0,341^{*}$ & $0,780^{* *}$ & $0,334^{*}$ \\
\hline
\end{tabular}

(1) Atributos de planta (MVF: produtividade de matéria verde de forragem e MSF: produtividade de matéria seca de forragem) e atributos físicos e químico do solo (Ma: macroporosidade, Mi: microporosidade, Pt: porosidade total, Dp: densidade de partícula, DMG: diâmetro médio geométrico, DMP: diâmetro médio ponderado, IEA: índice de estabilidade de agregados e COT: carbono orgânico total) avaliados nas camadas $1(0,00-0,10 \mathrm{~m})$ e $2(0,10-0,20 \mathrm{~m}) .{ }^{*} \mathrm{e} * *$ : significativo a 5 e $1 \%$, respectivamente. 
MVF $(230,0 \mathrm{~m})$, IEA2 $(186,0 \mathrm{~m})$, Pt1 $(142,0 \mathrm{~m})$, silte2 $(138,5 \mathrm{~m}), \operatorname{Ma} 1(124,0 \mathrm{~m})$ e silte1 $(111,0 \mathrm{~m})$, de modo que em trabalhos futuros os valores dos alcances empregados em pacotes geoestatísticos fomentem os pacotes computacionais utilizados na agricultura de precisão.

$\mathrm{Na}$ figura 1, são apresentados os mapas de krigagem simples das produtividades (MVF e MSF) de sorgo forrageiro. Verificou-se que a produtividade de matéria verde da forragem foi maior na região centro-leste e sul (Figura 1a), sendo os nônios 3, $5,6,8$ e 9 os quadrantes em que a produtividade ficou entre 99.336 e $118.380 \mathrm{~kg} \mathrm{ha}^{-1}$. As maiores produtividades de MSF foram observadas numa faixa entre os nônios 4, 5, 7 e 8 e em parte dos nônios 2 , 3 e $6 \mathrm{com}$ produtividade de 33.370 e $36.946 \mathrm{~kg} \mathrm{ha}^{-1}$ (Figura 1b).

Em consonância a isso, notou-se elevação do teor de areia2, silte1, silte2, Ma1 e Pt1. Em contraposição, verificaram-se nessas regiões valores menores de argila1 ( $>200$ e $<235 \mathrm{~g} \mathrm{~kg}^{-1}$ ), principalmente no centro da malha experimental, contrastando com os do índice de estabilidade de agregados observados, que, em sua maioria ficou abaixo de 0,665 (IEA1), para a segunda profundidade entre 0,560 e 0,755 (IEA2). De

Quadro 4. Parâmetros dos semivariogramas simples e cruzado ajustados para a produtividade de matéria verde da forragem de sorgo e de atributos físicos e químico de um Planossolo Hidromórfico

\begin{tabular}{|c|c|c|c|c|c|c|c|c|}
\hline \multirow[t]{2}{*}{ Atributo $^{(1)}$} & \multirow[t]{2}{*}{ Modelo $^{(2)}$} & \multirow{2}{*}{$\begin{array}{l}\text { Efeito pepita } \\
\qquad\left(C_{0}\right)\end{array}$} & \multirow{2}{*}{$\begin{array}{c}\text { Patamar } \\
\left(\mathrm{C}_{0}+\mathrm{C}\right)\end{array}$} & \multirow[t]{2}{*}{ Alcance $\left(\mathrm{A}_{0}\right)$} & \multirow[t]{2}{*}{$\mathbf{r}^{2}$} & \multirow[t]{2}{*}{$\mathbf{S Q R}^{(3)}$} & \multicolumn{2}{|c|}{$\mathrm{ADE}^{(4)}$} \\
\hline & & & & & & & $\mathrm{SQR}^{(3)}$ & Classe \\
\hline \multicolumn{9}{|c|}{$\mathrm{m}$} \\
\hline \multicolumn{9}{|c|}{ Gama (h) simples dos atributos de planta } \\
\hline $\operatorname{MVF}\left(\mathrm{kg} \mathrm{ha}^{-1}\right)$ & $\operatorname{Exp}$ & $1,800.10^{7}$ & $4,370.10^{8}$ & 230,0 & 0,589 & $1.900 .10^{6}$ & 95,8 & MA \\
\hline $\operatorname{MSF}\left(\mathrm{kg} \mathrm{ha}^{-1}\right)$ & Esf & $2,038.10^{7}$ & $4,801.10^{7}$ & 469,0 & 0,701 & $2,930.10^{14}$ & 57,6 & MO \\
\hline \multicolumn{9}{|c|}{ Gama (h) simples dos atributos do solo } \\
\hline Areia $1\left(\mathrm{~g} \mathrm{~kg}^{-1}\right)$ & Epp & $1,964.10^{3}$ & $1,964.10^{3}$ & - & - & - & - & - \\
\hline Areia $2\left(\mathrm{~g} \mathrm{~kg}^{-1}\right)$ & Esf & $2,100.10^{2}$ & $1,804.10^{3}$ & 232,0 & 0,788 & $3,884.10^{5}$ & 88,4 & MA \\
\hline Silte $1\left(\mathrm{~g} \mathrm{~kg}^{-1}\right)$ & Gau & 1,000 & $2,180 \cdot 10^{3}$ & 111,0 & 0,718 & $8,956.10^{5}$ & 100 & MA \\
\hline Silte $2\left(\mathrm{~g} \mathrm{~kg}^{-1}\right)$ & Gau & 1,000 & $1,932.10^{3}$ & 138,5 & 0,921 & $2,219.10^{5}$ & 99,9 & MA \\
\hline Argila $1\left(\mathrm{~g} \mathrm{~kg}^{-1}\right)$ & Gau & $8,930.10^{2}$ & $2,149.10^{3}$ & 389,0 & 0,689 & $8,352.10^{5}$ & 58,4 & MO \\
\hline Argila $2\left(\mathrm{~g} \mathrm{~kg}^{-1}\right)$ & Epp & $1,862.10^{3}$ & $1,862.10^{3}$ & - & - & - & - & - \\
\hline $\operatorname{Ma} 1\left(\mathrm{~m}^{3} \mathrm{~m}^{-3}\right)$ & Gau & $2,110.10^{-4}$ & $1,472.10^{-3}$ & 124,0 & 0,872 & $4,811.10^{-8}$ & 85,7 & MA \\
\hline $\operatorname{Ma} 2\left(\mathrm{~m}^{3} \mathrm{~m}^{-3}\right)$ & Epp & $3,234.10^{-3}$ & $3,234.10^{-3}$ & - & - & - & - & - \\
\hline $\operatorname{Mi} 1\left(\mathrm{~m}^{3} \mathrm{~m}^{-3}\right)$ & Epp & $9,700.10^{-4}$ & $9,700.10^{-4}$ & - & - & - & - & - \\
\hline Mi $2\left(\mathrm{~m}^{3} \mathrm{~m}^{-3}\right)$ & Epp & $1,280.10^{-3}$ & $1,280.10^{-3}$ & - & - & - & - & - \\
\hline $\operatorname{Pt} 1\left(\mathrm{~m}^{3} \mathrm{~m}^{-3}\right)$ & Gau & $1,100.10^{-6}$ & $2,052.10^{-5}$ & 142,0 & 0,857 & $4,602.10^{-7}$ & 100 & MA \\
\hline $\operatorname{Pt} 2\left(\mathrm{~m}^{3} \mathrm{~m}^{-3}\right)$ & Epp & $1,382.10^{-3}$ & $1,382.10^{-3}$ & - & - & - & - & - \\
\hline $\operatorname{Dp} 1\left(\mathrm{~kg} \mathrm{dm}^{-3}\right)$ & Epp & $9,420.10^{3}$ & $9,420.10^{3}$ & - & - & - & - & - \\
\hline Dp $2\left(\mathrm{~kg}^{3} \mathrm{dm}^{-3}\right)$ & Epp & $1,020.10^{-2}$ & $1,020.10^{-2}$ & - & - & - & - & - \\
\hline DMG $1(\mathrm{~mm})$ & Epp & $4,670.10^{-1}$ & $4,670.10^{-1}$ & - & - & - & - & - \\
\hline DMG $2(\mathrm{~mm})$ & Epp & $3,750.10^{-1}$ & $3,750.10^{-1}$ & - & - & - & - & - \\
\hline DMP $1(\mathrm{~mm})$ & Epp & $4,560.10^{-1}$ & $4,560.10^{-1}$ & - & - & - & - & - \\
\hline DMP $2(\mathrm{~mm})$ & Epp & $3,256.10^{-1}$ & $3,256.10^{-1}$ & - & - & - & - & - \\
\hline IEA 1 & Gau & $2,330.10^{-2}$ & $4,726.10^{-2}$ & 677,0 & 0,926 & $4,996.10^{-5}$ & 50,6 & MO \\
\hline IEA 2 & Esf & $1,010.10^{-2}$ & $2,720.10^{-2}$ & 186,0 & 0,444 & $1,550.10^{-4}$ & 62,8 & $\mathrm{AL}$ \\
\hline $\operatorname{COT} 1\left(\mathrm{~g} \mathrm{~kg}^{-1}\right)$ & Epp & $4,722.10$ & $4,722.10$ & - & - & - & - & - \\
\hline $\operatorname{COT} 2\left(\mathrm{~g} \mathrm{~kg}^{-1}\right)$ & Epp & $5,904.10$ & $5,904.10$ & - & - & - & - & - \\
\hline \multicolumn{9}{|c|}{ Gama (h) cruzado entre atributo de planta versus solo } \\
\hline MSF $=\mathrm{f}($ Argila 1$)$ & Gau & $-2,600.10^{3}$ & $-9,770.10^{3}$ & 306,5 & 0,498 & $8,730.10^{9}$ & 97,3 & MA \\
\hline
\end{tabular}

(1) Atributos de planta (MVF: produtividade de matéria verde de forragem e MSF: produtividade de matéria seca de forragem) e atributos físicos e químico do solo (Ma: macroporosidade, Mi: microporosidade, Pt: porosidade total, Dp: densidade de partícula, DMG: diâmetro médio geométrico, DMP: diâmetro médio ponderado, IEA: índice de estabilidade de agregados e COT: carbono orgânico total) avaliados nas camadas $1(0,00-0,10 \mathrm{~m})$ e $2(0,10-0,20 \mathrm{~m})$; ${ }^{(2)}$ Exp: exponencial; Esf: esférico; Epp: efeito pepita puro; e Gau: gaussiano; ${ }^{(3)} \mathrm{SQR}$ : soma dos quadrados dos resíduos; ${ }^{(4)} \mathrm{ADE}$ : avaliador da dependência espacial, sendo MO: moderada, AL: Alta, e MA: muito alta à dependência espacial. 

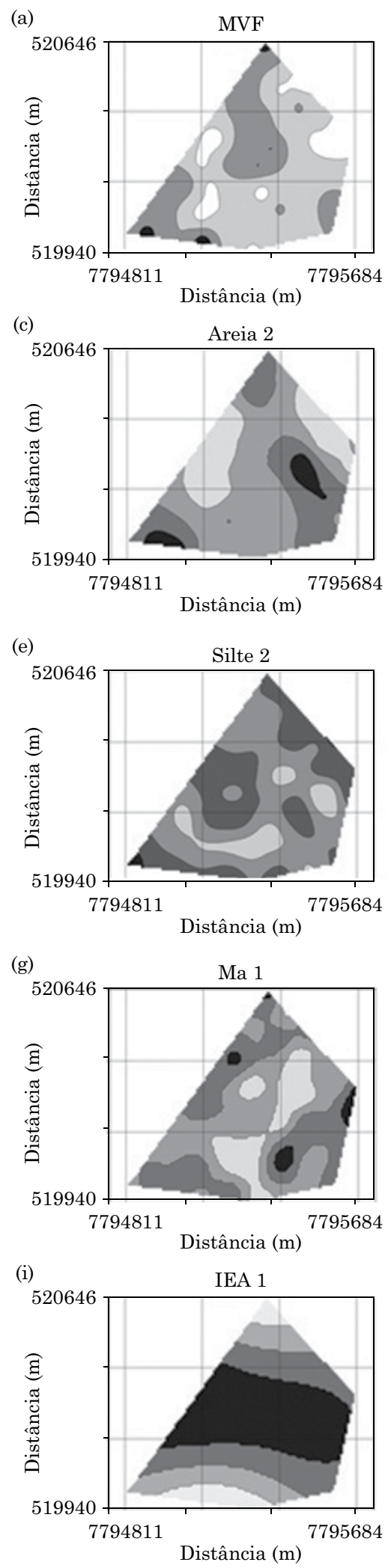

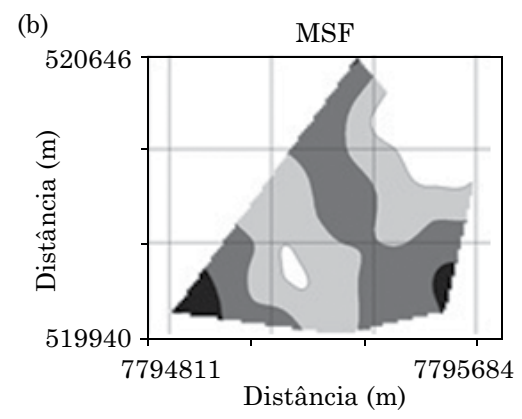

$\operatorname{MSF}\left(\mathrm{kg} \mathrm{ha}^{-1}\right)$
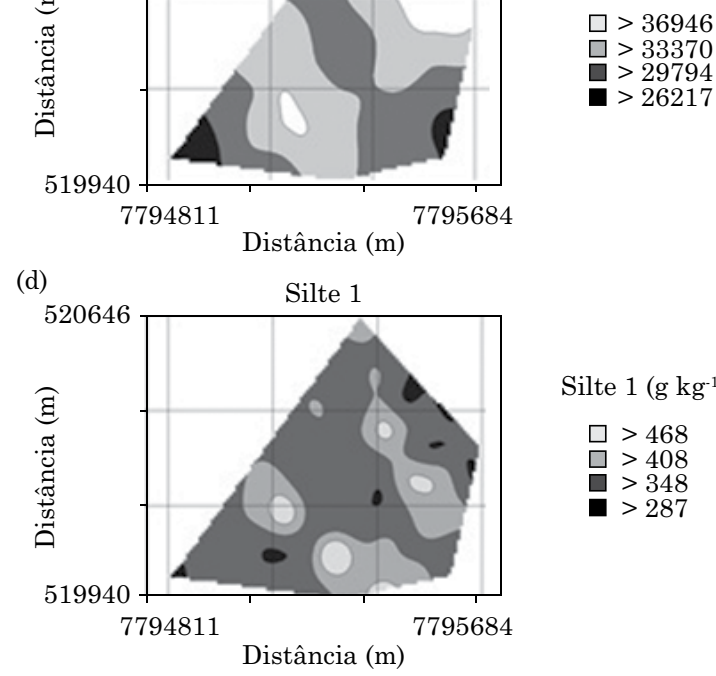

Silte $1\left(\mathrm{~g} \mathrm{~kg}^{-1}\right)$

Areia $2\left(\mathrm{~g} \mathrm{~kg}^{-1}\right)$

$$
\begin{aligned}
& \square>382 \\
& \square>344 \\
& \square>305 \\
& \square>267
\end{aligned}
$$

Silte $2\left(\mathrm{~g} \mathrm{~kg}^{-1}\right)$

$$
\begin{aligned}
& \square>456 \\
& \square>394 \\
& \square>332 \\
& \square>270
\end{aligned}
$$

$\operatorname{Ma} 1\left(\mathrm{~m}^{3} \mathrm{~m}^{-3}\right)$

$$
\begin{aligned}
& \square>0.135 \\
& \square>0.100 \\
& \square>0.065 \\
& \square>0.030
\end{aligned}
$$

(f)

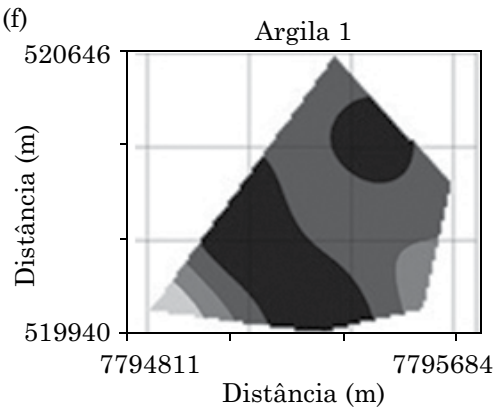

$\square>468$

$\square>408$

$>348$
$>$

(h)

Argila $1\left(\mathrm{~g} \mathrm{~kg}^{-1}\right)$

$$
\begin{aligned}
& \square>305 \\
& \square>270 \\
& \square>235 \\
& \square>200
\end{aligned}
$$

Pt $1\left(\mathrm{~m}^{3} \mathrm{~m}^{-3}\right)$

$$
\begin{aligned}
& \square>0.500 \\
& \square>0.440 \\
& \square>0.380 \\
& \square>0.320
\end{aligned}
$$



(j)



IEA2 $\left(\mathrm{m}^{3} \mathrm{~m}^{-3}\right)$

$\square>0.853$

$\square>0.755$

$\square>0.658$

$>0.658$
$>0.560$

Figura 1. Mapas de krigagem simples para produtividade de sorgo forrageiro e de atributos físicos de um Planossolo Hidromórfico. Atributos de planta (MVF: produtividade de matéria verde de forragem e MSF: produtividade de matéria seca de forragem) e atributos físicos do solo (Ma: macroporosidade, Pt: porosidade total e IEA: índice de estabilidade de agregados) avaliados nas camadas 1 (0,00-0,10 m) e $2(0,10-0,20 \mathrm{~m})$. 
(a)

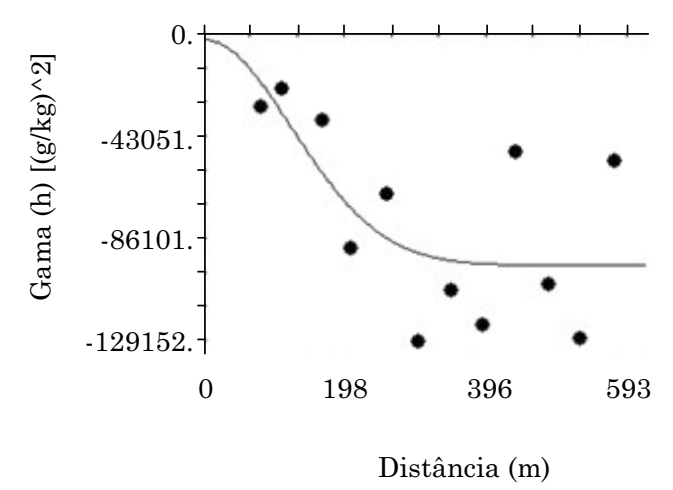

(b)

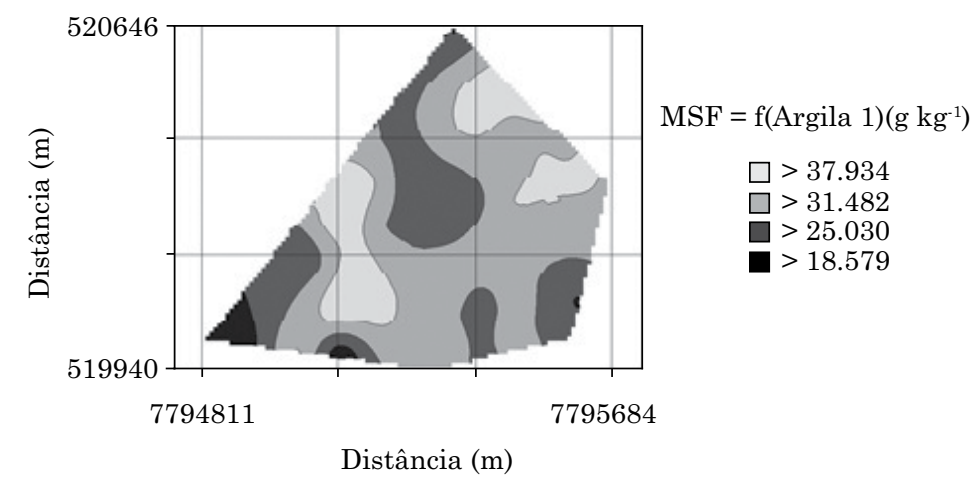

Figura 2. Semivariograma cruzado e mapa de cokrigagem da produtividade de matéria seca de forragem (MSF) de sorgo em função do teor de argila na primeira camada $(1=0,00-0,10 \mathrm{~m})$ de um Planossolo Hidromórfico.

acordo com Salton (2005), esses valores podem ser considerados resultantes de boa condição de agregação do solo.

No âmbito da cokrigagem (Figura 2), verificou-se a correlação espacial significativa e negativa apenas para o par MSF em razão da argila1 (MSF=f(argila1)), em que o coeficiente de determinação foi de 0,498 (Figura 2, Quadro 4). Pôde-se constatar que, espacialmente, a produtividade de matéria seca de forragem de sorgo pode ser estimada a partir da krigagem da argila na profundidade de 0,00-0,10 m, com $49,8 \%$ de probabilidade. Embora tenha ocorrido baixa correlação linear entre tais atributos, essa correlação foi significativa e negativa $\left(r=-0,292^{*}\right)$.

Outros autores identificaram que havendo alteração dos teores de areia, silte e argila as propriedades do solo como densidade e macroporosidade são influenciadas e dependendo do manejo e da cultura adotados nele podem proporcionar condições próximas às consideradas críticas ao crescimento radicular e ao desenvolvimento da parte aérea da planta (Secco, 2003; Collares, 2005; Suzuki, 2005). Isso possibilita inferir que, em condições de preparo convencional em Planossolo Hidromórfico, a cultura do sorgo tem sua produtividade influenciada negativamente com o aumento do teor de argila na profundidade de 0,00-0,10 $\mathrm{m}$.

\section{CONCLUSÕES}

O sorgo apresentou elevada produtividade de matéria verde $\left(106.832,0 \mathrm{~kg} \mathrm{ha}^{-1}\right)$ e matéria seca da forragem $\left(34.521,0 \mathrm{~kg} \mathrm{ha}^{-1}\right)$ com alta variabilidade, enquanto os atributos do solo apresentaram heterogeneidade baixa, alta e muito alta, dependendo da variável avaliada com base no coeficiente de variação.
A correlação linear entre os atributos de planta foi elevada e significativa, assim como houve correlação positiva entre os atributos de planta versus solo (matéria verde da forragem $\times$ areia na camada de 0,00-0,10 $\mathrm{m}$ e matéria seca da forragem $\times$ areia na camada de 0,00-0,10 m), e negativa (MSF $\times$ areia na camada de 0,00-0,10 m e MSF $\times$ matéria orgânica na camada de $0,00-0,10 \mathrm{~m})$, na produtividade de sorgo forrageiro.

Entre os atributos avaliados, a argila na profundidade de 0,00-0,10 $\mathrm{m}$ foi o melhor indicador espacial para estimar a variabilidade espacial da produtividade de matéria seca de forragem de sorgo, em sistema de cultivo convencional, em Planossolo Hidromórfico no ecótono Cerrado-Pantanal.

Para este trabalho, o teor de silte na camada de 0,00-0,10 $\mathrm{m}$ foi a variável dependente que apresentou o menor alcance $(111,0 \mathrm{~m})$ e, assim, recomenda-se que em futuras pesquisas em Planossolo Hidromórfico as distâncias entre as avaliações não sejam inferiores a esse valor.

\section{REFERÊNCIAS}

Avelino PM. Características produtivas e qualitativas de híbridos de sorgo (Sorghum bicolor, L. Moench) para produção de silagem, cultivados sob diferentes densidades de plantio [dissertação]. Araguaína: Universidade Federal do Tocantins; 2008.

Basso FC, Andreotti M, Carvalho MP, Lodo BN. Relações entre produtividade de sorgo forrageiro e atributos físicos e teor de matéria orgânica de um Latossolo do Cerrado. Pesq Agropec Trop. 2011;41:135-44.

Bamberg AL, Pauletto EA, Silva Gomes A, Timm LC, Pinto LFS, Lima ACR, Silva TR. Densidade de um Planossolo sob sistemas de cultivo avaliada por meio da tomografia computadorizada de raios gama. R Bras Ci Solo. 2009;33:1079-86. 
Cambardella CA, Moorman TB, Novak JM, Parkin TB, Karlen DL, Turco RF, Konopka AE. Field-scale variability of soil properties in Central Iowa Soils. Soil Sci Soc Am J. 1994;58:1501-11.

Campos MCC, Soares MDR, Oliveira IA, Santos LAC, Aquino RE. Spatial variability of physical attributes in Alfissol under agroforestry, Humaitá region, Amozonas state, Brazil. R Ci Agron. 2013;56:149-59.

Castro Filho C, Muzilli O, Podanoschi AL. Estabilidade dos agregados e sua relação com o teor de carbono orgânico num Latossolo roxo distrófico, em função de sistemas de plantio, rotações de culturas e métodos de preparo das amostras. $\mathrm{R}$ Bras Ci Solo. 1998;22:527-38.

Companhia Nacional de Abastecimento - Conab. Acompanhamento da safra brasileira de grãos [internet]. Brasília, DF: 2012 [acesso em 25 jul 2013]. Disponível em: http://www.conab.gov.br.

Companhia Nacional de Abastecimento - Conab. Acompanhamento da safra brasileira de grãos [internet]. Brasília, DF; 2013 [acesso em 1 nov 2013]. Disponível em: http://www.conab.gov.br.

Collares GL. Compactação em Latossolos e Argissolo e relação com parâmetros de solo e de plantas [tese]. Santa Maria: Universidade Federal de Santa Maria; 2005.

Dalchiavon FC, Carvalho MP, Nogueira DC, Romano D, Abrantes FL, Assis JT, Oliveira MS. Produtividade da soja e resistência mecânica à penetração do solo sob sistema plantio direto no cerrado brasileiro. Pesq Agropec Trop. 2011;41:8-19.

Empresa Brasileira de Pesquisa Agropecuária - Embrapa. Manual de métodos de análise de solo. $2^{\text {a }}$ ed. Rio de Janeiro: Centro Nacional de Pesquisa de Solos; 1997.

Empresa Brasileira de Pesquisa Agropecuária - Embrapa. Estação climatológica de Nhumirim Pantanal - MS. Corumbá: Centro de Pesquisa Agropecuária do Pantanal; 2002.

Empresa Brasileira de Pesquisa Agropecuária - Embrapa. Sistema brasileiro de classificação de solos. $3^{\mathrm{a}}$ ed. Rio de Janeiro: Centro Nacional de Pesquisa de Solos; 2013.

Grable AR, Siemer EG. Effects of bulk density aggregate size and soil water suction on oxygen diffusion, redox potential and elongation of corn roots. Soil Sci Soc Am J. 1968;2:18-186.

Guareschi RF, Brasil RB, Perin A, Ribeiro JMM. Produção de silagem de híbridos de milho e sorgo sem nitrogênio de cobertura em safra de verão. Pesq Agropec Trop. 2010;40:541-6.

$\mathrm{GS}^{+}$: Geostatistics for environmental sciences. $7^{\mathrm{a}}$ ed. Plainwell: Gamma Design Software; 2004.

Isaaks EH, Srivastava RM. An introduction to applied geostatistics. New York: Oxford University Press; 1989.

Kemper WD, Rosenau RC. Aggregate stability and size distribution. In: Klute A, editor. Methods of soil analysis. Madison: America Society of Agronomy; 1986. Pt 1. p.425-42.

Köppen W. Climatologia. Buenos Aires: Fondo de Cultura Económica; 1931. van Lier QJ, editor. Física do solo. Viçosa, MG: Sociedade Brasileira de Ciência do Solo; 2010.

Lima CLR, Pillon CN, Suzuki LEAS, Cruz LEC. Atributos físicos de um Planossolo Háplico sob sistemas de manejo comparados aos do campo nativo. R Bras Ci Solo. 2008;32:1849-55.

Montanari R, Panachuki E, Lovera LH, Oliveira IS, Bonini CSB. Variabilidade espacial da produtividade de sorgo e de atributos físicos em um Planossolo. R Agro@mb on-line. 2013;7:252-61.

Pimentel-Gomes F, Garcia CH. Estatística aplicada a experimentos agronômicos e florestais: Exposição com exemplos e orientações para uso de aplicativos. Piracicaba; Fundação Escola de Agricultura Luiz de Queiroz; 2002.

Pedrotti A, Mello Júnior AV. Avanços em ciência do solo: A física do solo na produção agrícola e qualidade ambiental. São Cristóvão: Universidade Federal de Sergipe, 2009.

Polo JRV; Garcia DB. Variabilidad espacial de propiedades físicas y químicas en suelos de la granja experimental de la Universidad del Magdalena (Santa Marta, Colombia). R Acta Agron. 2010;202155, nmj3:449-56.

Robertson GP. Geostatistics for the environmental sciences. Plainwell: Gamma Design; 1998.

Salton, JC. Matéria orgânica e agregação do solo na rotação lavoura-pastagem em ambiente tropical [tese]. Porto Alegre: Universidade Federal do Rio Grande do Sul; 2005.

Secco D. Estados de compactação de dois Latossolos sob plantio direto e suas implicações no comportamento mecânico e na produtividade de culturas [tese]. Santa Maria: Universidade Federal de Santa Maria; 2003.

Shatar TM, McBratney AB. Empirical modeling of relationships between sorghum yield and soil properties. Prec Agric. 1999;1:125-52.

Schlotzhaver SD, Littell RC. SAS system for elementary statistical analysis. $2^{\mathrm{a}}$ ed. Cary: Statistical Analysis Systems; 1997.

Shapiro SS, Wilk MB. An analysis of variance test for normality: Complete samples. Biometrika. 1965;52:591-611.

Silva Neto SP, Santos AC, Silva JEC. Variabilidade espacial da fertilidade de Neossolo Quartzarênico em função da substituição do cerrado por pastagem. R Eng Agric. 2011a;19:334-47.

Silva Neto SP, Santos AC, Leite RLL, Dim VP, Cruz RS, Pedrico A, Neves Neto DN. Análise espacial de parâmetros da fertilidade do solo em região de ecótono sob diferentes usos e manejos. Semina Ci Agron. 2011b; 32:541-52.

Suzuki LEAS. Compactação do solo e sua influência nas propriedades físicas do solo e crescimento e rendimento de culturas [tese]. Santa Maria: Universidade Federal de Santa Maria; 2005.

Yeomans JC, Bremner JM. A rapid and precise method for routine determination of organic carbon in soil. Commun Soil Sci Plant Anal. 1988;19:1467-76. 